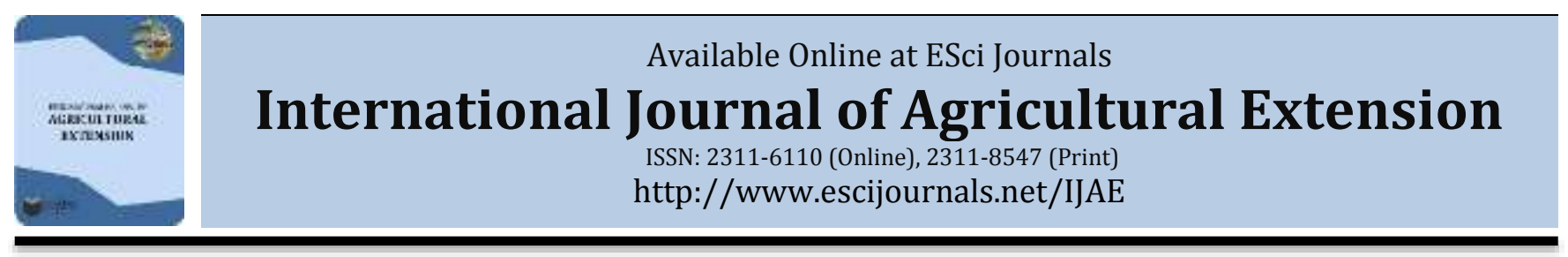

\title{
TACTICS FOR EFFICIENT AGRICULTURE OUTREACH TARGETING SMALL AND MIDSIZE FARMERS; A CASE STUDY IN THE COACHELLA VALLEY
}

\author{
Miguel A. Garcia*, Robert Pence \\ Coachella Valley Resource Conservation District, United States of America.
}

\begin{abstract}
A B S T RA C T
A successful agriculture outreach program was implemented in the Coachella Valley among small acreage Hispanic farmers. The main objective of this program was to help farmers conserve water through active soil moisture monitoring through the use of tensiometers. To overcome the challenges of agriculture outreach, this project incorporated a one-on-one, hands-on approach with an individualized curriculum. By regularly visiting the farmers in their fields we were able to truly understand their needs and to demonstrate to them we were honestly concerned about the issues they face. This approach slowly made the farmers feel comfortable working with us and more receptive towards advice given. An important component of the project is to involve the farmer in the actual soil moisture monitoring as much as possible. By allowing farmers to actively monitor the moisture content of their soils, we were able to give the farmers a sense of empowerment and ownership of the project. This approach helped farmers trust the technology and feel comfortable using it to make irrigation decisions. Up to date, all of the participating farmers have reported using tensiometers as the main decision-making tool at the time of irrigation.
\end{abstract}

Keywords: Valley, projects, soil moisture, monitoring.

\section{INTRODUCTION}

Considering that global population is projected to reach 9.8 billion by the year 2050, experts all over the globe are beginning to wonder how countries will be able to feed their increasing populations (Faisal \& Parveen. 2004, Godfray et al., 2010, Schmidhuber \& Tubiello. 2007). Although increasing the allocations for farmland seems to be the most logical solution, transforming natural habitats into farmland can have disastrous consequences in the environment (Clay, 2004). With this in mind, a better solution would be to maximize the productivity of current farmlands. To accomplish this, farmers would need to manage their land and water as efficiently as possible. Unfortunately, water scarcity and extreme weather conditions lead to uncertainties that force farmers to make extreme decisions, decisions that can damage the fertility of the land (Nelson et al., 2010). As a result of this, several conservation agencies have been established around the country to help farmers

* Corresponding Author:

Email: mgarcia@iercd.org

(C) 2018 ESci Journals Publishing. All rights reserved. manage their land and natural resources more sustainably. Examples of these agencies include the Resource Conservation Districts in California and Natural Resources Conservation Service, a branch of the United States Department of Agriculture. Conservation agencies like these work diligently to develop programs aimed at assisting farmers to increase their yields while reducing impacts on natural resources. Unfortunately, while the development of conservation programs may be difficult, the implementation phase may prove to be even more difficult due to reservations from farmers to participate in governmental programs (Leeuwis, 2004). Developing working relationships with farmers can be one of the most difficult tasks for a conservation agency, particularly when targeting small and midsize producers (Van den Ban \& Hawkins, 1996). In some cases, these farmers have never received any assistance from outside groups and they have a general sense of distrust towards local agencies reaching out to them. In addition to this, a lot of these farmers have learned how to take care of their fields through information passed on from generation to generation, making them less receptive 
towards new information (Ison \& Russell, 1999). Moreover, crop losses have the potential to have a greater negative impact on small and midsize farmers than on large producers (Ali \& Byerlee, 1991). The high dependence on the success of a few acres of cropland can make small and midsize farmers apprehensive about implementing changes, particularly when involving technology and techniques not familiar to them. With this in mind, any agency or individual interested in developing and implementing agriculture outreach programs should take into consideration these factors and realize that there will be a fair degree of resistance before developing successful, ongoing relationships with the farming community.

In the Coachella Valley in California, being an extremely arid region, some farmers face limitations in water availability, poor soil nutrient retention, poor soil water retention and elevated soil salinity levels; issues that severely affect the productivity of the land. Although there are several farmers in the area that have the financial resources to address these issues, there is a big group of farmers that do not have the necessary resources to do so. These farmers depend on the success of small fields, often less than 40 acres, to make a living. Due to the fact that the majority of these farmers do not speak English and/or a general sense of distrust towards local agencies, some farmers have not received the assistance they need to improve their productivity and manage their natural resources more efficiently. Recognizing this, the Coachella Valley Resource Conservation District (CVRCD) partnered up with the Natural Resources Conservation Service (NRCS) agency in Indio, CA to develop an outreach program called the Root Water Project that could reach out to small acreage producers, particularly Hispanic farmers in the area. The main objective of the Root Water Project was to assist farmers with their irrigation water management while developing relationships of mutual trust to help farmers be more receptive towards receiving assistance from the CVRCD, NRCS and other local agencies.

A critical aspect of this project was to identify what would be the most appropriate extension method to effectively transfer information to help small and midsize farmers have better control of their irrigation water. In the case of these producers, a top-down extension approach does not make the most sense since a lack of farmer feedback will limit the ability of the project to be applied to a variety of different local conditions (Fraser et al., 2006). On the other hand, a feedback approach in which input from farmers is considered would help develop a more robust project capable of meeting the needs of a diverse group of farmers (Anderson \& Feder, 2004). In line with developing extension programs that empower farmers and gives them a more active role, a participatory approach can be implemented. This approach allows farmers to gain the necessary knowledge and confidence to apply newly obtain knowledge in a way that best fit their needs (Hagmann et al., 1996). In the case of the project described here, it was decided that a feedback/participatory extension approach would be the most effective to address the needs of small and mid-size producers and allow farmers to become self-reliant when it comes to managing their irrigation. The objective of this paper is to demonstrate how a one-on-one, hands-on approach can facilitate the introduction and adoption of new technology, soil moisture sensors in this case, among farmers that have not received much previous outside assistance.

\section{METHODOLOGY}

This paper demonstrates how a one-on-one, hands-on approach, such as in the Root Water Project, can be implemented to motivate farmers to adopt new technologies. The increase in knowledge of farmers about soil-plant-water relationships and how they use that information to make irrigation decisions was assessed by conducting a pre and post assessment. It was also assessed the extent to which the participating farmers adapted the new technology to make irrigation decisions and the factors that affected the extent of adoption.

Root Water Project Methods: Recognizing that Hispanic farmers are the largest demographic of limited resources in the Coachella Valley, the Root Water project was designed to help small-acreage, Spanish speaking family farmers conserve water and improve crop health. The practical objective of the project is for each participating farmer to gain a better-applied understanding of crop water use and effective, evidencebased, irrigation scheduling for the soils, climates and crops on his or her own farm.

The project was developed and is managed by the Coachella Valley Resource Conservation District (CVRCD) in close partnership with the Natural Resources Conservation Service (NRCS) Indio field office. The initial, pilot year of Root Water was funded by 
NRCS-California through a Cooperative Agreement in 2016. The project was extended for a second and third year through additional funding from NRCS and support from the Coachella Valley Mountains Conservancy California Proposition 1 fund for water conservation.

Three aspects of the project design define Root Water. First is the focus on small-acreage, Spanish-speaking farmers, largely from the underserved farm communities of Mecca, Thermal and Oasis on the east side of the Coachella Valley. Next, is an approach to an agricultural extension that emphasizes hands-on, infield, one-on-one, active teaching and learning over an extended period of time. Finally, is an evaluation and feedback component that is integrated into all aspects of project implementation. At heart, Root Water is a project of active teaching and learning between CVRCD, NRCS and small-acreage Spanish-speaking farmers in the Valley. The farmers were able to learn valuable technical information from the CVRCD and NRCS staff members while these staff members learned about the individual needs of each farmer and how to best disseminate information to this community of farmers. The CVRCD Root Water project manager meets with each participating farmer on his own farm at least 5 times during the project year. In between farm visits, the CVRCD contacts each farmer by telephone to get updates on farmer experiences, to answer any questions the farmer might have and to maintain the relationship between the farmer and project manager. Discussion topics for each on-farm visit are determined by farmer interest and by a loose curriculum structure that addresses issues of soil moisture monitoring, water-soilcrop relationships and interpretation of soil moisture data, all as they relate directly to the farmer's experience with his own soils, crops and farm management circumstances.

Soil Moisture Monitoring Technology Tensiometers are the primary tools for monitoring the soil moisture on each farm. By measuring surface tension, tensiometers basically indicate how hard plant roots have to work to pull moisture from the soil. Depending on the soil types and crops, multiple sets of two or three tensiometers are strategically placed at various locations on each farm. Each tensiometer set includes at least one unit to measure irrigation water at the root zone of each crop. A second unit measures the excess irrigation water that percolates below the reach of plant roots. Participant farmers are expected to monitor and record tensiometer data at least three times each week throughout the duration of the project. The readings provide a springboard for in-field discussion and mutual teaching and learning between the Root Water project manager and the farmers about the variables that impact crop water use and the strategies for efficient irrigation management on each farm. Farmers keep the tensiometers upon project completion.

The decision-making team composed of NRCS and CVRCD employees decided that the transparent mechanical operation of tensiometers would provide a more effective learning tool than more technologically advanced, operationally opaque electronic soil monitoring technologies. They could more effectively help farmers get an intuitive sense of the physical processes of water moving through the root zones of their crops. Basically, the tensiometers provide a teaching springboard for the project manager and farmer to explore and discuss water conservation and crop water needs. This and all of the project design decisions were filtered through a shared commitment among team members to effective teaching and learning. Farmer recruitment Farmer selection and recruitment fell almost completely on the NRCS field staff. The NRCS staff has extensive experience working in the agricultural regions of the California desert and has established working relationships with many of the farmers in the target cohort. They were instrumental in identifying and making initial contact with farmers who might be willing to participate in the project. The criteria for farmer selection were:

- Small acreage $(<80$ acres $)$

- Primarily Spanish-speaking

- Need for assistance with irrigation water management

- Ability to benefit from assistance with irrigation water management

- Limited or no previous support from traditional Ag and water conservation agencies in the Valley

- Willingness to participate

- Commitment to follow-through

Extension Approach Shared Commitment to LevelLearning Level learning field helps define the extension approach of Root Water. Agricultural extension is the professional communication intervention to support farmers in voluntarily developing and adopting strategies and technologies to address agricultural problems. The management team shared a recognition that it was asking farmers to adopt an unfamiliar 
technology, a new evidence-based strategy of irrigation management and to develop a new understanding of the crop-soil-water relationships for their farms. Rather than use an "expert-driven" information dumping approach to communication in the project, the team believed that the Root Water farmers were more likely to adopt these changes if they were provided with hands-on, in-field support over an extended period of time as they investigated, adapted and incorporated these changes into the irrigation decision making for their own farms.

Co-Investigators. As much as possible, the Root Water project manager assumed a role of co-investigator with the farmers as they explored how irrigation water moved through the soils on the farm. Initial tensiometer placement was determined by the NRCS field engineer based on irrigation system design and soil mapping for each farm. But after initial placement, farmers were supported in experimenting with the tensiometers. Farm visit field notes indicate that the project manager encouraged farmers to completely stop irrigation in some crop areas in order to see the connections between tensiometer readings, soil moisture and crop appearance. At the start of the project, a number of the farmers irrigated daily. Their soil never had a chance to dry out so there was no chance for them to see for themselves if the tensiometers accurately indicated changes in soil moisture content. Along the same lines, the project manager encouraged farmers to examine soil samples from their crop root zones so they could physically see if there was a relationship between tensiometer data and soil moisture content. During the early farm visits, the project manager worked together with the farmer in interpreting tensiometer readings.

Transfer of Responsibility. Field notes from throughout the project year indicate a progressive transfer of project responsibility and technological expertise from the Root Water project manager to each of the farmers. All of the participating farmers had extensive experience farming on their land and were experts in their own crop production. The project manager brought technical expertise in irrigation water quality, management and soil moisture monitoring and analysis. In the early farm visits, the project manager clearly took the lead in tensiometer installation, maintenance, interpretation of tensiometer data and analysis of water movement through the soils on each farm. As the project year progressed, the farmers increasingly assumed more responsibility for interpreting the irrigation management implications of their tensiometer data. The project manager became an in-field resource If-needed. On-farm, Site-Specific. Almost all Root Water extension was site-specific, hands-on and in the field. The objective of Root Water is to help farmers improve their irrigation management decisions for their specific soils, and their specific crops on their own farms. More generalized knowledge about water conservation and water-soilcrop relationships emerged from this site-specific experience, but the project design team recognized that all farm management decisions are, by necessity, sitespecific and that farmers are more likely to adopt and sustain irrigation water use strategies that are introduced, adapted and practised within the circumstances they face on their own farms.

Physical, Hands-on. Farmers and the project manager got down in the dirt together to install the tensiometers. They helped each other pump out excess air from the tensiometers as part of ongoing maintenance. They dug down to test the root level soil moisture by feel. Almost all Root Water extension was physical, hands-on and in the field.

Extended, Repetitive. The project manager made at least 5 on-farm visits to each participating farm throughout the project year. In between visits he made follow-up phone calls with each farmer. This repetitive contact helped support and reinforce the working relationships within the project. It also helped support and reinforce farmer use of an unfamiliar technology and new irrigation management strategy. This stands in contrast to a more typical one-time presentation of new technology or farm management strategy with little or no on-farm follow-up or support. As a standard part of each farm visit the project manager and farmer inspected each tensiometer station, provided any needed maintenance and examined and interpreted tensiometer data that the farmer had logged in the previous two months. During each visit, the project manager also asked each farmer to describe if and how he was using the tensiometer data in his irrigation decisions. This ongoing dialogue and extended follow-up helped support farmers as they learned and tried new irrigation strategies.

Flexible, Responsive, Individualized curriculum. The Root Water "curriculum" is individualized and responsive. The project manager plans for each farm visit with some general topics he wants to explore. These 
topics include maintenance of tensiometers, interpretation of tensiometer data, how water moves through specific soils, the agronomic, economic and ecological impacts of over-irrigation. But this general curriculum is individualized for each farmer depending upon farmer interest and previous knowledge of the topic. And this general curriculum is not set in stone. The project manager is encouraged to seize learning opportunities as they arise whether those opportunities are directly related to the planned curriculum topic or not. Whatever farm management issue is of immediate concern, the farmer can become the topic of the farm visit that day. This flexibility and responsiveness help increase the relevance and impact of Root Water extension.

Human Process. Again, critical in all aspects of the approach to farmer extension used in Root Water is the recognition that the learning and sustained adoption of efficient and effective irrigation management strategies is not a technical and mechanistic process but rather an organic, human process that takes time, trustworthy relevant information, repetition, follow-up support and a teaching / learning relationship of respect.

Data Collection. Each Root Water farmer is provided with a book for logging tensiometer data. Each book contains a soil map identifying the types and locations of all soils on each farm, a set of instructions describing tensiometer operation and a number of data sheets for farmer collection of tensiometer data. These data sheets are for recording tensiometer readings, irrigation dates and weather. All written materials in the log books are in Spanish. Data collected by the farmer was used by the NRCS field staff to create graphs, customized for each farmer, of the extended impacts of irrigation on soil moisture content at the surface and root levels over time. Basically, these soil moisture graphs of tensiometer data indicate how long water was available to crop roots in the soil on each farm. These graphs were used as feedback mechanisms for the farmers to demonstrate that the data they collected was useful and to visually present the movement of moisture through the soil profile on each farm over time.

Project implementation: The 10 farmers who initially agreed to participate in the pilot year of the project farm a total of 110 acres. The mean farm size is 9.6 acres. All of the project acreages is planted in dates. Five of the farmers use well-water, five use canal. Six irrigate through drip systems, two irrigate by furrow. One uses flood and one uses a combination of drip and flood. Most of the farms are located near the communities of Thermal, Oasis and Mecca. One farm is located in Indio Hills and one in Sky Valley. All of the farmers have, in the past, participated in at least one NRCS farmer-incentive program. Of the original 10 farmers, one was replaced within the first month of the project because he repeatedly missed scheduled on-farm appointments with the CVRCD Project Manager. Halfway through the project year, two additional farmers were removed from the project for similar reasons. The project manager could not reach them to arrange farm visits. Eight of the original farmers completed the full project year. The inconsistent communication around farm visit scheduling was a source of frustration for the management team and the Root Water project manager. The primary point of contact between the project and participating farmers is the CVRCD Project Manager. The Project Manager, sometimes with NRCS field staff assistance, arranged and conducted the on-farm visits with each farmer. He also developed and implemented an individualized "curriculum" for each farm visit that was, as much as possible, responsive to immediate farmer concerns and interests. With an extension approach that emphasizes active farmer learning and is dependent on a relationship of mutual respect between the farmer and Root Water project manager, the project manager plays a crucial role in how the project actually operates in the field. In this approach, the project manager's social skills and teaching values and skills are just as important as his technical knowledge and skills in soils, water and irrigation management.

Field Notes. Project data were also collected through formal field notes written by the project manager within 24 hours of each farm visit. These notes specifically describe project manager observations during the visit, the topics covered in discussion, any questions or issues raised by the farmer, successes or challenges the farmer is facing in use or logging of tensiometer data, anything the project manager thought worked well or not so well during the visit and any specific follow-up recommendations for the next farm visit. These notes were used by the CVRCD District Manager and the Root Water management team to fine-tune project implementation for each farmer.

Comparative Survey. To provide some baseline and comparative data of project impacts, all project farmers completed, on the first farm visit, a 50-question survey 
and on the final farm visit, a 56-question survey. Both surveys were administered face-to-face by the Root Water project manager. All survey questions were openended and were designed to assess farmer knowledge about soils-water-crop relationships, the consequences of over-irrigation, current irrigation management practices, use of tensiometers. In addition, the postproject survey asked farmers for suggestions about how the project might better meet their needs. There were no attempts to collect data on overall farmer water use. Early in project planning the management team recognized that there were not enough project resources to track down farmer water use records for comparison. There was also recognition that isolating project impacts through comparative water use data would be complicated, again beyond the limited project resources. Since Root Water was designed to increase farmer knowledge and increase farmer use of evidence-based irrigation decision making, the team decided to focus on qualitative measurement of these factors through farmer self-reports, project manager in-field observations and survey data. In Year 2, the management team hopes to collect farmer water use data for a more quantitative measure of project impacts.

Farmer Meeting. The same design process that established the full project was used to organize the first Root Water farmer education meeting. In early November of the pilot year, over 27 farmers gathered for "Breakfast and A Conversation on Irrigation" sponsored by CVRCD. CVRCD provided breakfast burritos, pan dulce, coffee and juice at no charge to all participants. NRCS and CVRCD field staff gave three 20-minute presentations on various aspects of irrigation water management and the Root Water project. All presentations were in Spanish. Since the presenters knew many of the attending farmers, the event really did become a conversation, with farmers asking questions and describing some of their experiences with Root Water. The event was held outdoors on an organic date farm near Mecca. The meeting was scheduled for early November, a time when most local farmers have completed the fall date harvest. At the recommendation of the NRCS District Conservationist, NRCS and CVRCD field staff contacted local farmers individually both inperson and via telephone to invite them to the open event. Flyers describing the event were distributed through local irrigation supply dealers, feed stores and agrochemical dealers. In addition, two local Spanish radio stations ran Public Service Announcements about the event. Organizers considered the event a success. Farmers appeared engaged throughout the two-hour conversation. Many stayed after the last speaker to talk with each other and to apply for enrolment in the Year 2 of Root Water.

\section{RESULTS AND DISCUSSION}

Prior to participation in Root Water, most of the farmers had no formal training in soils or irrigation management. Most learned about farming through family members, former employers or trial and error. Comparison of pre and post project survey data indicate increases in depth and complexity of farmer knowledge about the soils on their own farms, water movement through those soils, consequences of over-irrigation on crop health, the movement of fertilizer and other agrochemicals through soils, the value of root zone soil moisture monitoring and the operation of tensiometers. For example, one farmer in the pre-survey responded to a question about the consequences of over-irrigation by noting, "There is no such thing as over-irrigation. You should add as much water as you can." By the end of Year 1, the same farmer responded to the same question by pointing out that over-irrigation limits root oxygen and promote the growth of bacteria that can harm the crop. Post survey results show that the greatest change in farmer knowledge was in the interpretation of tensiometer data. Prior to Root Water, few of the original farmers had any experience with tensiometers or any type of soil moisture monitoring, by the end of the pilot year, all correctly explained the irrigation implications of various tensiometer readings. The increase in farmer knowledge was not consistent across all topics though. For example, in post-survey responses, none of the farmers mentioned compromised groundwater quality as a consequence of over-irrigation.

A major objective of Root Water is to support farmers in adopting evidence-based irrigation water management. Prior to project participation, most of the farmers reported that they irrigated by set schedule or calendar. Typical was one farmer who said simply "I just follow my schedule and put the same amount of water every time I irrigate" This was echoed by most of the other farmers. Two of the farmers reported that they included the general appearance of their crops in their irrigation decisions. When asked about the factors he considers in deciding when to irrigate his date crop, one farmer laughed and said, "I just guess. The success of my farm is 
nothing but an accident." Initial tensiometer readings at the beginning of the project indicated that all of the farmers were over-irrigating their crops.

At the end of the pilot year, all of the Root Water farmers included tensiometer readings as an important piece of evidence in their decisions about when to irrigate. In many cases this allowed farmers to skip scheduled irrigations. In the post-project survey, the farmer who earlier said his irrigation scheduling was based on guesswork reported, “Now I don't guess when I need to irrigate. I just look at the tensiometers and see if the numbers are not too high. If they aren't higher than 15 or 20, I can skip a day or two and then check again. That way I can sometimes skip a few weeks before irrigating again." Another farmer explained, "I now look at the tensiometers to see if I need to irrigate or not. At the beginning of the summer, I think I skipped one or two weeks because the tensiometers were telling me that the soil was still humid." Another farmer agrees, [the tensiometers] "let me know when the soil is still wet so I can skip irrigation until the soil really needs it." At the Root Water farmer education meeting, this farmer reported that the tensiometer data allowed him to skip up to 6 scheduled irrigations in the past year. He noted,"I now look at the tensiometers before irrigating and this helps me make the necessary preparations with plenty of time. When I can see that the tensiometer readings are starting to go up it means I'm going to have to irrigate soon. I have already skipped a lot of irrigations because the tensiometer tells me that the soil is still wet and this has saved me a lot of money and work.

Another farmer explained, "I am already making some changes in my irrigation practices. I walk around and look at the tensiometers to see if I can push my soil a little further before adding water. I know that some farmers don't like doing that, especially with the fruit coming out, but I trust the tensiometers and I feel very comfortable relying on them to decide when to irrigate". Still, another added, "I now look at the tensiometers every time I need to irrigate to make sure it is not too soon. I trust the measurements and I now feel more relaxed because I can know exactly if my soil is humid or not". One farmer took a more cautious approach to the use of tensiometer data in his irrigation decisions. He commented, "This year I wanted to learn how to use the tensiometers and how water moves through my soil. Now that I know how tensiometers work I will be much less hesitant to use them to make modifications in my irrigation because I know they will not affect my productivity which was a concern for me at the beginning of the project."

At the same time, many farmers spoke of the benefits of keeping a data log of the soil moisture readings throughout the year. One farmer singled out the NRCS graphing as an especially helpful aspect of the project, "it helped me see when the peak moments were occurring each month during the year." Another echoed, "it allowed me to compare results for different months and see how quickly I was losing water over a long period of time." Beyond the value of the data, required logging also encouraged farmers to monitor their tensiometers on a consistent basis. As one farmer noted, the logging, "forces me to keep a closer eye on irrigation." It also helps reinforce a habit of observing and recording of evidence for irrigation decision making. Another farmer added, "Keeping a record helps me see the trends in my field, but more importantly, knowing that I have to take the numbers makes me be more consistent. Otherwise, I would forget and probably not take the numbers as regularly."

"Saving Water, Saving Money". Almost all of the participating farmers voiced strong support for the project. Some singled out the support they received from the Root Water project manager, "You need someone to touch base with and to help you keep track of the readings and how things are going over time." Another farmer added, [the project manager] "was a very beneficial resource because sometimes I wasn't sure if I was doing things right and I could check with him". Others focused more on the project results, "I am now more consistent in how I irrigate. I follow the tensiometers to see if the plants need any water and I can see now that the plants look much healthier than before."

All thought that other farmers would benefit from Root Water, though some pointed out the project would be of limited value to large acreage farmers. One farmer commented “It probably wouldn't help big farmers. They have all the money for a successful operation without much external help." Another agreed, [Root Water] "will benefit small farmers that don't have the money to hire helpers like big companies." Of the eight farmers who completed the pilot year, seven re-enrolled for a second year of project participation. (As of this writing, the Root Water project manager has been unable to reach the remaining farmer). When asked "why" he signed up for a 
second year, one farmer replied, "I want to continue saving water and saving money." Another agreed, "I want to continue conserving water." One farmer said, "I am a young farmer and I want to continue learning. Any help is very welcomed." Another added, "I want to apply what I have been learning this year when I change my irrigation system next year" Yet another farmer explained, "it will help me be more organized in my irrigation management, in my record keeping. It will help me make the right decisions."

\section{CONCLUSIONS}

Root Water largely met the objectives of increasing farmer knowledge about the relationships between the soil, irrigation water and crops and increasing farmer use of evidence-based irrigation water management. Rather than irrigating solely by habit or calendar regardless of soil moisture content, most of the participating farmers incorporated, to varying degrees, tensiometer data in their irrigation decisions. Many of the farmers reported that this gave them new insight into their crop water use and allowed them to skip a number of scheduled irrigations, saving water, money and most probably reducing percolation of excess ag water into groundwater supplies.

A number of factors came together to make Root Water a successful pilot. First is the partnership between NRCS and CVRCD. NRCS (California) provided funding for the project and NRCS Indio field staff were actively engaged in all aspects of project design including development of the Root Water farmer education meeting. NRCS provided the technical expertise in soils and water. CVRCD provided administrative guidance for the project and theoretical foundation for extension / outreach. This partnership could be seen on a daily basis with frequent communication on Root Water issues among CVRCD and NRCS which are both housed in the Indio USDA Service Center office. Though they did not always agree, members of the Root Water management team worked well together and brought an effective mix of experience and expertise into each project design decision.

Perhaps most importantly, all members of the management team placed a high value on farmer learning and recognized that sustained project impact would depend on how much farmers understood, internalized and assumed ownership of evidence-based irrigation management. All project design decisions from a choice of speakers at the farmer education meeting to format for the farmer logbooks, from a choice of tensiometers for soil moisture monitoring to the choice of extension approaches were selected for potential impact on farmer learning and successful adoption of evidence-based irrigation management.

The extension approach reflected this shared commitment to active learning. The Root Water management team shared a recognition that a top-down technology or information transfer process of "dump and run" was rarely effective. As if to underscore this point, one of the Root Water farmers volunteered that another government agency had previously installed two tensiometers on his farm but no one trained him how to use or maintain them. As a consequence, the tensiometers sat unused in his date orchard for years in need of maintenance, a testament to a technology transfer without follow-up support. In contrast, the Root Water extension approach was designed to provide farmers with trustworthy technical information, extended project structure and in-field support so they could experiment with the new technology and irrigation strategies. The extension approach used in Root Water was:

- Site-specific, working with the specific soils/crops on the farmers' own farm

- On-farm (there were no classroom or seminar room PowerPoint presentations)

- Hands-on (a physical process of doing rather than a solely intellectual process of telling)

- Repetitive (revisiting key topics of tensiometer use and irrigation management on each farm visit)

- Horizontal (project manager and farmer as coinvestigators, as compared to a traditional top-down approach in which the project manager is the source of knowledge and deposits that knowledge with the farmers)

- Flexible and responsive to farmer concerns and interests

- Over an extended period of time

- Grounded in a relationship (the project manager nurtured a teaching / learning relationship of mutual respect with each of the farmers).

It was determined that implementing a one-on-one, hands-on approach gave this project an opportunity to successfully motivate farmers to use new technology to make more informed irrigation decisions. The extensive personalized technical training allowed the farmers to become comfortable with the technology and trust the measurements obtained. The fact that these farmers had 
received very little to no assistance in the past was a challenge that was overcome by slowly gaining the trust of farmers through constant interaction.

Acknowledgements: This project would have not been possible without the financial support from the USDA NRCS and the Coachella Valley Mountains Conservancy. Many thanks to Raul Alvarado, Juan Segoviano and Ricardo Ortiz from the NRCS office in Indio, CA, for their support and technical assistance.

\section{REFERENCES}

Ali, M. \& Byerlee, D. (1996). Economic Efficiency of Small Farmers in a Changing: A survey of Recent Evidence. Journal of International Development, 3(1), 29-37.

Anderson, J.R. \& Feder, G. (2004). Agricultural Extension: Good Intentions and Hard Realities. The World Bank Research Observer. 19(1), 41-60.

Clay, J.W. (2004). World Agriculture and the Environment: A Commodity-by-Commodity Guide to Impacts and Practices. Island Press.

Faisal, I. \& Parveen, S. (2004). Food Security in the Face of Climate Change, Population Growth, and Resource Constrains: Implications for Bangladesh. Journal of Environmental Management, 34(4), 487-498.

Fraser, E.D.G., Dougill, A.J., Mabee, W.E., Reed, M. \& McAlpine, P. (2006). Bottom Up and Top Down: Analysis of participatory process for sustainability indicator identification as a pathway to community empowerment and sustainable environment management. Journal of Environmental Management, 78(2), 114-127.
Godfray, C.J., Beddington, J.R., Crute, I.R., Haddad, L., Lawrence, D., Muir J.F., Pretty, J., Robinson, S., Thomas, S.M. \& Toulmin, C. (2010). Food Security: The Challenge of Feeding 9 Million People. Science, 28 January.

Hagmann, J., Chuma, E. \& Murwira, K. (1996). Improving the Output of Agricultural Extension and Research Through Participatory Innovation Development and Extension; Experiences from Zimbawe. Europ. Journal of Agricultural Education and Extension, 2(4), 15-23.

Ison, R. \& Russell, D., (1999). Agricultural Extension and Rural Development: Breaking out of Knowledge Transfer Traditions. Cambridge University Press.

Leeuwis, C. (2004). Communication for Rural Innovation: Rethinking Agricultural Extension. Wiley Blackwell.

Nelson, G.C., Rosegrant, M.W., Palazzo, A., Gray, I., Ingersoll, C., Robertson, R., Tokgoz, S., Zhu, T., Sulser, T.B., Ringler, C., Msangi, S. \& You, L. (2010). Food Security, Farming and Climate Change to 2050: Scenarios, Results, Policy Options. International Food Policy Research Institute.

Schmidhuber, J. \& Tubiello, F.N. (2007). Global food security under climate change. PNAS, 104(50), 19703-19708.

Van den Ban, A.W. \& Hawkins, H.S. (1996). Agricultural Extension. Wiley-Blackwell. 